\title{
A Corpus-Based Cooperative Learning Model for English Vocabulary Teaching in Chinese Higher Education
}

\author{
YUAN Fang \\ University of Shanghai for Science and Technology, Shanghai, China
}

\begin{abstract}
Vocabulary teaching is a most significant part of language education. However, the effect of English vocabulary teaching in most Chinese universities is not very satisfactory. This study aims to explore the use of corpora, Range, and cooperative learning models in English vocabulary teaching in Chinese higher education. For that purpose, we shall firstly work out a revised list of words to learn for the students with the help of famous corpora and Range. Then, cooperative learning models can be employed to best motivate students in the vocabulary learning process.
\end{abstract}

Keywords: corpora, cooperative learning models, Range, vocabulary teaching

\section{Introduction}

Vocabulary is no longer a victim of discrimination and neglect in second language learning research, nor in language teaching. Lexis has been deemed as crucial to any language acquisition process, native, or non-native. According to Singer (1985), the understanding of vocabulary accounts for 39\% of one's reading comprehension and the identification of words accounts for $28 \%$ of one's reading speed. In view of this, vocabulary teaching plays a vital and irreplaceable part in language teaching, including the teaching of English as a foreign language.

Although all language teachers have intuitively known and agreed that a solid vocabulary is absolutely necessary in every stage of language learning, many students either have not fully recognized the importance of vocabulary learning or are intimidated by the task of memorizing a huge number of English words. Researchers have reached the consensus that the effect of English vocabulary teaching at the level of higher education in China is not as satisfactory as can be expected. Studies have shown that most English learners in China are rather weak in the size, diversity, and stylistic features of English words (Wen, 2006; Wu \& Zou, 2009). This problem can be attributed to many reasons, among which the most noticeable ones are the inadequate glossary following each unit in the English textbooks and students' lack of motivation in vocabulary learning. In this paper, the author is to propose to effectively raise students' motivation in vocabulary learning with the help of Range, cooperative learning models, and well-known corpora, such as BNC (The British National Corpus) and COCA (Corpus of Contemporary American English).

\section{Research Background}

Many scholars have done researches about vocabulary teaching worldwide. However, based on the search results of research papers on www.cnki.net in the last two decades, the author has found that admittedly 
vocabulary teaching has become a heated topic in recent years, most Chinese scholars have focused on the macro aspects, such as the application of certain linguistic theories in vocabulary teaching (Li, 2000; Peng, 2002; Liang, 2002), but very few research papers deal with the micro-aspect, that is, the conduction of vocabulary teaching in the actual teaching process, for instance, how to select the words for teaching and how to teach the words effectively and efficiently in the classroom.

The cooperative learning models are some of the most extensively implemented and researched models of teaching in recent years. These models have consistently demonstrated the ability to foster students' positive development in self-esteem, communication skills, and most importantly, in their interest and motivation in study. Cooperative learning, as a teaching strategy for classroom instruction and management, has been used in a wide variety of teaching contexts. Ever since it was introduced into schools in China in the early 1990s, many scholars and educators have been exploring its application in various subjects and in education of different levels. But there has been very little research into the application of cooperative learning model in vocabulary teaching in EFL classrooms whether in China or in other countries. Based on literature review at home and abroad, the author proposes to combine the concept of cooperative learning with vocabulary teaching in the intensive reading course for English majors in China. The author believes that the cooperative learning models can not only increase students' interest in vocabulary learning, but also help students learn more effectively and efficiently.

\section{Theoretical Basis}

This research is based on the frequency hypothesis and the noticing hypothesis. According to the frequency hypothesis, the order of L2 acquisition is determined by the frequency with which different linguistic items occur in the input (Hatch \& Wagner, 1976). According to the noticing hypothesis, learners cannot learn the grammatical features of a language unless they notice them. Noticing alone does not mean that learners automatically acquire language; rather, the hypothesis states that noticing is the essential starting point for acquisition (Schmit, 1990). In light of these two hypotheses, this research aims at maximizing the frequency of students' encounter with the words to be taught in order to achieve desirable teaching and learning effect.

\section{Research Design}

\section{Object of Study}

As the author teaches sophomore English majors the course of intensive reading in a Chinese university and the textbook that is chosen for the course is entitled An Integrated English Course, which is published by Shanghai Foreign Language Education Press, the author is to take the example of this textbook to illustrate how to make good use of corpus and the cooperative learning models for English majors using this textbook. However, this does not mean that the teaching model cannot be applied to non-English majors or students using other textbooks.

\section{Selection of Target Words}

Each unit in An Integrated English Course textbooks is provided with a glossary designed by the compliers of the series of books. The words in the glossaries are supposed to be the most important words in the texts and presumably new words for most students. However, the words that are to be included in the glossaries are chosen by the compliers based on their subjective judgment, instead of on objective studies, such as vocabulary tests. Therefore, some words in the glossary are either too easy or not very important as they are 
seldom used. In addition, the definition given for some words in the glossary are actually not the meaning employed for the words concerned in the texts, which is sure to confuse many students and render the entry not only useless but also misleading. In view of this, the author suggests that the teacher can make familiarization with words in the glossaries a self-study task for the students before class and select important words from the texts based on Range, a program for vocabulary statistics and The Teaching Syllabus for English Majors in Higher Education. According to the Teaching Syllabus, English majors in universities in China should know 5,500 to 6,500 words and should be capable of using 3,000 to 4,000 of them freely in their language production. We will mainly select new words from the texts that are new and a bit challenging to most students, mostly words that can be classified into Level 3 to Level 8 of Range, but exclude those that are too difficult, for instance, those that can be classified into Level 9 to Level 14 of Range. In this way, we can manage to work out a revised list of new words for classroom teaching.

\section{Implementation}

The aim of employing the cooperative learning models is to encourage every student to actively participate in the learning process and therefore achieve the best learning effect.

Step One-Introduce the Cooperative Learning Model. The teacher will explain to the students how this learning model works in the classroom and stress to them that the interdependence of students working together is the key to the effect of this learning model.

Step Two-Name, teach and practice targeted social skills. At this time, the teacher will describe the social skills that students will need and focus on during group study. These skills include active listening, providing constructive comments, etc. If necessary, the skills can be taught, modelled, and practiced in class.

Step Three-Assign students to expert and home groups. Each student will be part of two groups-an "expert" group (which will focus on learning and sharing information about the words assigned to this group by the teacher) and a "home" group (which will comprise one member of each expert group).

In this process, the teacher might intentionally bring students of different characteristics together in order to promote the students' learning due to their differences in a complementary manner. The differences the teacher can take into account include but are not limited to gender, ability, personality, and learning style.

Step Four-Assemble expert groups. Presumably, all members of the same expert group have consulted popular corpora, such as BNC and COCA and have gathered information concerning the meaning, usage, collocation, word formation, etymology, etc. They can share their individual work within their expert groups so that when they finish with their discussion in the expert group, everybody has become an expert in terms of the words assigned to them. Within the expert groups, students should create a teaching handout or some other product to use to teach their home group members the words they have mastered in their expert groups.

Step Five-Experts teach in their home groups. During this step, the teacher can review the teaching materials students have prepared in their respective expert groups to make sure that they are complete and accurate. After that, the students can teach other members of their home groups all the information they have gathered in their expert groups. Hopefully, in the end, each member of the home groups will master all the words the teacher previously assigned to the expert groups.

\section{Conclusion}

In the whole cooperative learning process, each student will have to frequently encounter the words chosen by the teacher whether in their own preparation, discussion with expert group members or in their 
teaching process in home groups, which can ensure the frequency with which different linguistic items (hereby words) occur in the input. Moreover, as every student has his/her own part to play both in his/her expert group and in the home group, he/she will definitely be motivated to explore all important information related to the words assigned to him/her and probably be more attentive in learning from fellow classmates in home groups. In this way, the students' learning interest will be greatly increased.

\section{References}

Hatch, E., \& Wagner, G. (1976). Explaining sequence and variation in second language acquisition. Language Learning, 4(Special Issue), 39-47.

Kong, L., \& Qin, H. W. (2013). Using corpora in vocabulary teaching: On a lexical grading basis. Foreign Language Learning Theory and Practice, 4(4), 58-63.

Laufer, B. (1996). What's in a word that makes it hard or easy: Some intralexical factors that affect the learning of words. Applied Linguistics, 22, 1-26.

Li, Z. H. (2000). Semantics and teaching of English vocabulary. Journal of Gansu Normal University, (3), 92-97.

Liang, X. B. (2002). Cognitive linguistics and vocabulary teaching in ESL. Foreign Languages and Their Teaching, (2), 35-39.

Peng, J. W. (2002). Application of connectionist theory in vocabulary teaching. Foreign Language World, (4), 45-50.

Schmit, R. (1990). The role of consciousness in second language learning. Applied Linguistics, 1, 17-46.

Singer, M. G. (1985). Relationship between the standard scores of peabody picture vocabulary test-revised and wide range achievement test. Journal of Clinical Psychology, 41(5), 691-693.

Wen, Q. F. (2006). Vocabulary variation across speech and writing by English majors. Foreign Languages and Their Teaching, (7), 9-13.

Wu, J., \& Zou, Q. (2009). A corpus-based register study of Chinese learners' spoken and written English: Lexical density and frequency. Shandong Foreign Language Teaching Journal, 30(1), 8-13. 